\title{
THE PROCESSING OF BEACH SAND FROM SRI LANKA FOR THE RECOVERY OF TITANIUM USING MAGNETIC SEPARATION
}

\author{
W.A.P.J. PREMARATNE* and N.A. ROWSON \\ Department of Chemical Engineering, The University of Birmingham, \\ Edgbaston, Birmingham B15 2TT, UK
}

(Received 7 November 2002; Accepted 3 December 2002)

\begin{abstract}
An investigation has been carried out to study the mineralogical and chemical characteristics of beach sand deposits from Sri Lanka and application and optimisation of different magnetic separators (induced roll magnetic separator and disc magnetic separator) to improve the recovery of titanium from the deposit. Commercial grade titanium concentrates could be achieved employing both induced roll and disc magnetic separators. However, the titanium recovery increased greatly in the magnetic fraction with a titanium content of commercial grade (up to $63.9 \% \mathrm{TiO}_{2}$ ) when paramagnetic titanium-bearing minerals were separated from beach sand using the disc magnetic separator. The results of the mineralogical and chemical analysis tests for the beach sand deposit indicated that $71 \%$ of beach sand was smaller than $355 \mu \mathrm{m}$ in particle size and more than $99 \%$ of titanium content of the deposit was contained in this fraction.
\end{abstract}

Keywords: Beach sand; Sri Lanka; Titanium; Magnetic separation

\section{INTRODUCTION}

The most important economic titanium-bearing minerals are ilmenite $\left(\mathrm{FeTiO}_{3}\right)$ and rutile, anatase and brookite $\left(\mathrm{TiO}_{2}\right)$, which, although they all have same formula, differ in their crystalline structure. Leucoxene is an oxidation product of ilmenite and is composed of finely crystalline rutile. Ilmenite commonly occurs altered to mixtures of $\mathrm{TiO}_{2}, \mathrm{FeO}$ and $\mathrm{Fe}_{2} \mathrm{O}_{3}$, with the $\mathrm{TiO}_{2}$ content increasing from 49 to $75 \%$ as mineral oxides and iron are leached out by groundwater. Altered ilmenite $(60-75 \%$ $\left.\mathrm{TiO}_{2}\right)$ is usually amorphous, but the leucoxene $\left(76-90 \% \mathrm{TiO}_{2}\right)$ stage begins to show the definite crystalline structure of rutile. The name "pseudorutile" has been proposed for ilmenite alteration products containing up to $92 \% \mathrm{TiO}_{2}$. The final alteration products exhibit either the rutile or anatase structure and contain $92-96 \% \mathrm{TiO}_{2}[1,2]$.

More than $90 \%$ of titanium ore is processed into titanium dioxide pigment, known as titanium white, a brilliant white, non-toxic pigment used as a whitening or opacifying agent in paints, lacquers, plastic, textiles, paper etc. However, about $5 \%$ of the world

*Corresponding author. E-mail: WAP087@bham.ac.uk 
production of titanium minerals goes to make titanium metal which has wide industrial application in the aircraft industry [1-3].

The bulk of the world's production of titanium minerals is derived from beach sand, although ilmenite is also mined from hard rock deposits in Canada and Norway [3]. The existence in many places on the coasts of Sri Lanka of natural concentrates of titanium-bearing mineral sands such as ilmenite and rutile with a high degree of purity has been know since as far back as 1903 [4]. The major deposits are on the north-east coast at Pulmoddai in Sri Lanka, which have been exploited economically since 1958 [5,6]. The deposit extends along the beach for $7.2 \mathrm{~km}$ with an average width of $50 \mathrm{~m}$ and a maximum width of $250 \mathrm{~m}$. It covers an area of $3.2 \mathrm{~km}^{2}$ and has an even thickness of $6 \mathrm{~m}$ over Precambrian crystalline rock with no overburden. The deposit is very high grade, with a heavy mineral content of $80 \%$ and a composition of $70-72 \%$ ilmenite, $8-10 \%$ zircon, $8 \%$ rutile, $1 \%$ sillimanite and $0.3 \%$ monazite [1].

High-intensity magnetic separation is widely used throughout the mineral sands industry for the treatment of heavy mineral concentrates [7]. In Sri Lanka, ilmenite is recovered using wet magnetic separation at the Pulmoddai plant [6]. In some plant operations, dry magnetic separation is employed, particularly for recovering titanium-bearing minerals such as ilmenite and leucoxene from heavy mineral concentrates.

Beach sand deposit economic value depends not only on the amenability of the ore to separation, a process that is controlled by the mineralogical characteristics of the deposit. Over the last few decades systematic work on the beach sand deposits of Sri Lanka has been carried out to study their distribution and mineralogy by the Geological Survey Department of Sri Lanka [8]. Some studies [5] have investigated the offshore area in front of the presently exploited Pulmoddai beach deposit mineralogically and chemically.

It is apparent from previous work that there is still a lack of detailed mineralogical and chemical analysis of Sri Lankan beach sand deposits and investigations of the recovery of titanium-bearing minerals from the sand using magnetic separation. This investigation was intended to study the mineralogical and chemical characteristics of the beach sand deposit from Sri Lanka and application and optimisation of different magnetic separators (induced roll magnetic separator and disc magnetic separator) to improve the recovery of titanium from the deposit effectively, efficiently and economically.

\section{EXPERIMENTAL PROCEDURE}

\section{Mineralogical and Chemical Analysis}

The heavy mineral beach sand sample from Pulmoddai deposit in Sri Lanka, which was supplied by Lanka Mineral Sand Ltd, was used for this experimental work. Particle size analysis was carried out on beach sands by the dry sieving method. The particle size fraction $-355+63 \mu \mathrm{m}$ was considered for the mineralogical and chemical analysis. These were carried out according to the flowsheet given in Fig. 1. Dense medium separation was first carried out using 1,1,2,2-tetrabromoethane (TBE) for the float-sink analysis. The heavy fraction from dense medium separation was used for the lowintensity magnetic separation using a hand magnet to separate highly magnetic minerals. The remaining weakly magnetic fraction was separated into four individual 


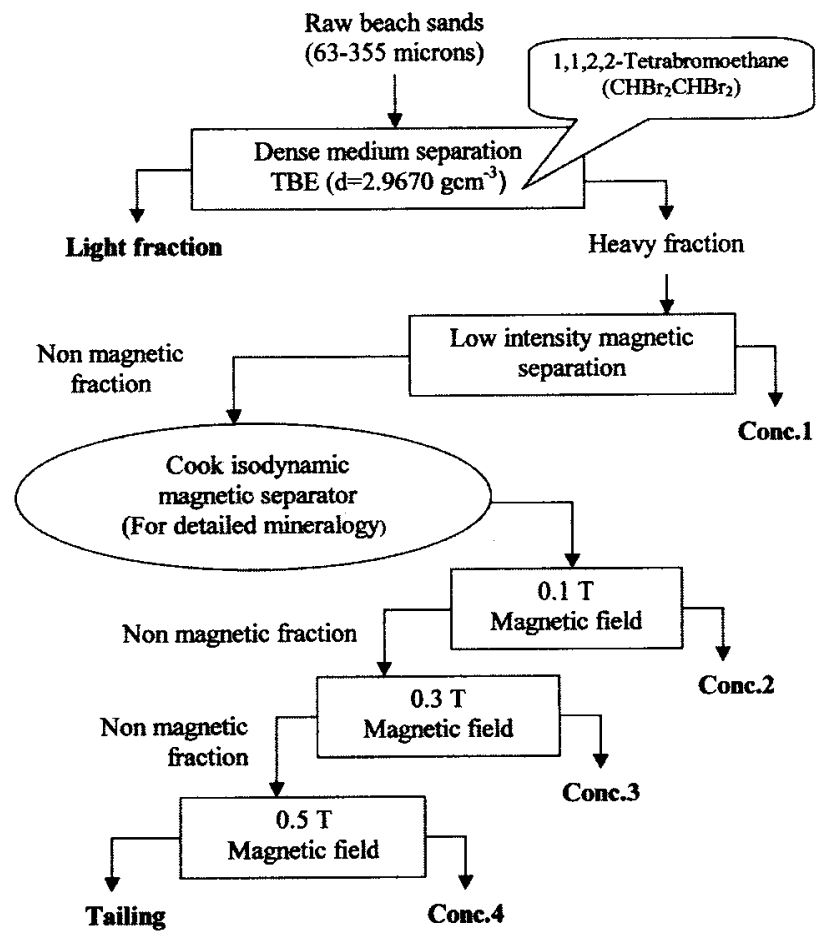

FIGURE 1 Flowsheet of mineralogical analysis of beach sand.

fractions employing a Cook isodynamic magnetic separator (Frantz isodynamic magnetic separator) at magnetic field strengths of $0.1,0.3$ and $0.5 \mathrm{~T}$.

The six fractions separated for mineralogical analysis were chemically assessed to determine titanium and iron content. Mineral samples were decomposed by fusion with $\mathrm{KHSO}_{4}$ at $800^{\circ} \mathrm{C}$ and the melt was dissolved in $20 \% \mathrm{H}_{2} \mathrm{SO}_{4}$ acid [9]. Titanium analysis was carried out in a UV/Visible spectrophotometer based on the yellow complex formed by titanium with $\mathrm{H}_{2} \mathrm{O}_{2}$ [10]. Total iron was analysed utilising an atomic absorption spectrophotometer. The relative errors of analysis of titanium and iron were \pm 3.5 and $\pm 2.0 \%$ respectively.

X-ray powder diffraction techniques, employing a Philips Analytical X-ray machine, were used to examine each individual fraction to determine mineral phases.

\section{Magnetic Separation}

\section{Induced Roll Magnetic Separator}

A Boxmag Rapid Ltd. induced roll magnetic separator (Fig. 2) was employed to separate paramagnetic titanium-bearing minerals from the deposit. In this separator magnetic field strengths of up to $1.4 \mathrm{~T}$ were attainable in the gap between feed pole and roll. A representative sample of raw beach sands of particle size smaller than $355 \mu \mathrm{m}$ in diameter was used for each test run. Samples were fed on to the roll and non-magnetic particles were thrown off the roll, whereas magnetics were gripped, carried out of the influence of the field and deposited as magnetic product. 


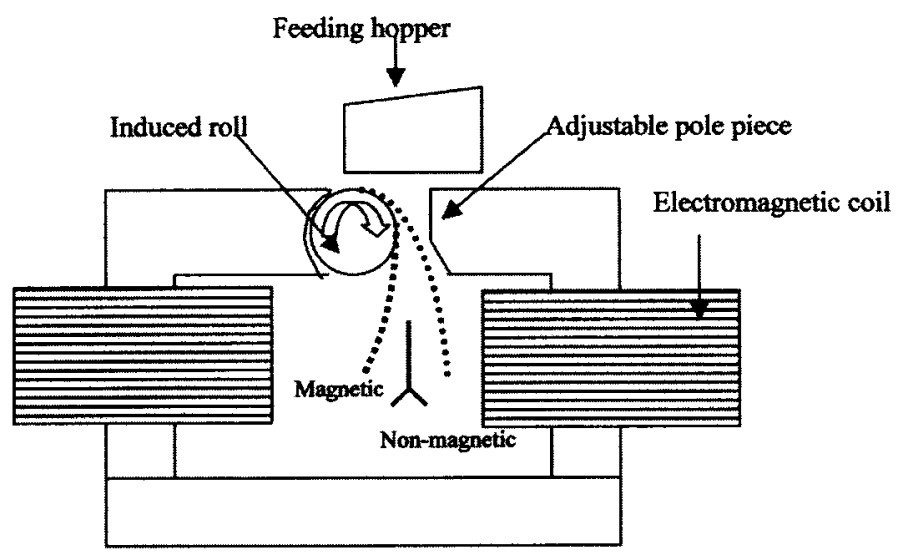

FIGURE 2 Induced roll magnetic separator.

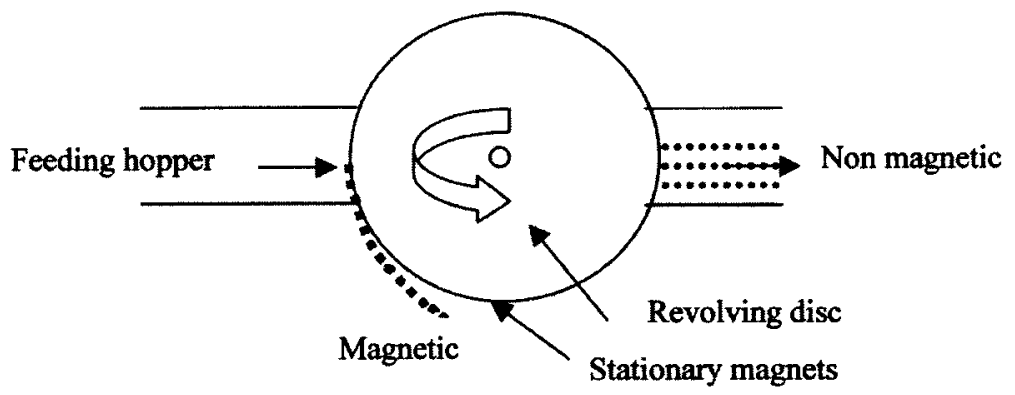

FIGURE 3 Disc magnetic separator.

\section{Disc Magnetic Separator}

The second unit utilised in this study for the recovery of titanium-bearing minerals from the deposit was a disc magnetic separator (Fig. 3). The magnetic field strength of this unit was varied from 0.2 to $0.8 \mathrm{~T}$ in the gap between disc and flat pole stationary magnets placed below the disc. Representative beach sand samples of particle size smaller than $355 \mu \mathrm{m}$ were used for this test work. Samples were fed through a vibrating feeder. Magnetic minerals were picked up and transported by the revolving disc and deposited as a magnetic fraction, whereas non-magnetic materials followed the path of the feed and were discharged by the gravitational force.

\section{RESULTS AND DISCUSSION}

\section{Mineralogical and Chemical Analysis}

The particle size distribution of Sri Lankan raw beach sand is given in Fig. 4. A maximum of $29.1 \%$ by weight of raw beach sand was found in particle size fraction of $-125+90 \mu \mathrm{m}$. It was found that more than $71 \%$ mass of raw beach sands is attributable to particle size smaller than $355 \mu \mathrm{m}$. Therefore, in the recovery of titanium minerals from the deposit the comminution process is not needed due to weathering and natural concentration of the beach sand deposit. 


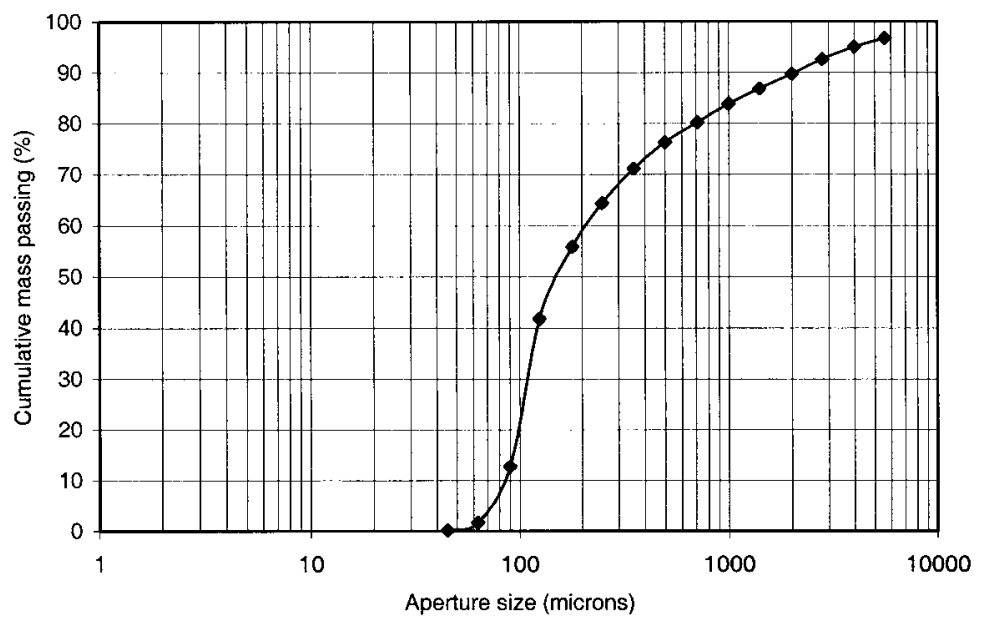

FIGURE 4 Particle size distribution of beach sand.

TABLE I Titanium and iron distribution of beach sand

\begin{tabular}{lccccc}
\hline $\begin{array}{l}\text { Sieve aperture size } \\
(\mu \mathrm{m})\end{array}$ & $\begin{array}{c}\text { Weight } \\
(\%)\end{array}$ & $\begin{array}{c}\text { Ti grade } \\
(\%)\end{array}$ & $\begin{array}{c}\text { Ti distribution } \\
(\%)\end{array}$ & $\begin{array}{c}\text { Fe grade } \\
(\%)\end{array}$ & $\begin{array}{c}\text { Fe distribution } \\
(\%)\end{array}$ \\
\hline+1000 & 16.2 & 0.43 & 0.37 & 3.82 & 6.43 \\
$-1000+710$ & 3.6 & 0.28 & 0.05 & 1.32 & 0.49 \\
$-710+500$ & 3.9 & 0.33 & 0.07 & 1.29 & 0.52 \\
$-500+355$ & 5.1 & 0.55 & 0.15 & 1.51 & 0.81 \\
$-355+250$ & 6.8 & 2.85 & 1.03 & 3.00 & 2.11 \\
$-250+180$ & 8.5 & 10.74 & 4.92 & 6.72 & 5.97 \\
$-180+125$ & 14.1 & 26.50 & 20.02 & 12.11 & 17.76 \\
$-125+90$ & 29.1 & 34.20 & 53.36 & 14.55 & 44.07 \\
$-90+63$ & 11.1 & 30.54 & 18.09 & 16.88 & 19.41 \\
-63 & 1.6 & 21.87 & 1.93 & 14.09 & 2.42 \\
Total & & & & & 100.00 \\
\hline
\end{tabular}

The titanium and iron distribution of raw beach sand was studied. The results of titanium and iron distribution in different size fractions of raw beach sand are presented in Table I. It was found that titanium and iron assays were 0.43 and $3.82 \%$ respectively in the $+1000 \mu \mathrm{m}$ particle size fraction. No obvious change in titanium and iron grades was observed for the particle size fractions of $-1000+710$, $-710+500$ and $-500+355 \mu \mathrm{m}$. In all these three fractions, the titanium grade was less than $1 \%$. The highest titanium assay $(34.20 \%)$ was found in the particle size fraction of $-125+90 \mu \mathrm{m}$. According to the titanium distribution of the deposit, more than $99 \%$ of titanium content of the deposit was contained in the particle size fraction smaller than $355 \mu \mathrm{m}$.

Therefore, a particle size smaller than $355 \mu \mathrm{m}$ of raw beach sand is selected for economical recovery of titanium from the deposit by physical and chemical processing. Chemical and mineralogical analysis of Sri Lankan beach sand deposit was investigated and results are given in Tables II and III.

Dense medium separation of beach sand in the $-355+63 \mu \mathrm{m}$ size range gave a light fraction (density $<2.9670 \mathrm{~g} \mathrm{~cm}^{-3}$ ) of $23.5 \%$ by weight. Only quartz was found in this 
TABLE II Chemical analysis of different fractions of beach sand (refer to Fig. 1)

\begin{tabular}{lccc}
\hline $\begin{array}{l}\text { Mineral } \\
\text { fraction }\end{array}$ & $\begin{array}{c}\text { Weight } \\
(\%)\end{array}$ & $\begin{array}{c}\text { Ti grade } \\
(\%)\end{array}$ & $\begin{array}{c}\text { Fe grade } \\
(\%)\end{array}$ \\
\hline Light fraction & 23.5 & 1.13 & 1.99 \\
Conc.1 & 0.7 & 19.47 & 40.42 \\
Conc. 2 & 13.8 & 37.07 & 25.69 \\
Conc.3 & 25.5 & 38.54 & 24.77 \\
Conc.4 & 15.5 & 39.29 & 17.73 \\
Tailing & 21.0 & 28.33 & 2.3 \\
\hline
\end{tabular}

TABLE III X-ray diffraction analysis of different fractions of beach sand (refer to Fig. 1)

\begin{tabular}{ll}
\hline Mineral fraction & Mineral phases $($ types of minerals) \\
\hline Light fraction & Quartz $\left(\mathrm{SiO}_{2}\right)$ \\
Conc. 1 & Magnetite $\left(\mathrm{Fe}_{3} \mathrm{O}_{4}\right)$, ilmenite $\left(\mathrm{FeTiO}_{3}\right)$ \\
Conc. 2 & Ilmenite $\left(\mathrm{FeTiO}_{3}\right)$ \\
Conc. 3 & Ilmenite $\left(\mathrm{FeTiO}_{3}\right)$, Pseudorutile $\left(\mathrm{Fe}_{2} \mathrm{Ti}_{3} \mathrm{O}_{9}\right)$ \\
Conc. 4 & Ilmenite $\left(\mathrm{FeTiO}_{3}\right)$, Pseudorutile $\left(\mathrm{Fe}_{2} \mathrm{Ti}_{3} \mathrm{O}_{9}\right)$ \\
Tailing & Rutile $\left(\mathrm{TiO}_{2}\right)$, zircon $\left(\mathrm{ZrSiO}_{4}\right)$ \\
\hline
\end{tabular}

light fraction according to the X-ray diffraction analysis data given in Table III. The titanium $(1.13 \%)$ and iron $(1.99 \%)$ content in the light fraction is partly due to the presence of lock particles and inefficient separation.

Low-intensity magnetic separation of raw beach sand using a hand magnet $(0.04 \mathrm{~T}$ magnetic field strength) showed that less than $1 \%$ mass of highly magnetic minerals is present in the deposit. The magnetite and the ilmenite minerals were found in this magnetic fraction (Conc.1).

The magnetic fractions (Conc.2, Conc.3 and Conc.4) separated by a Cook isodynamic magnetic separator at different magnetic field strengths contain the bulk of the ilmenite. According to the chemical analysis only insignificant variations of the titanium content occur in these three different fractions, whereas the iron content decreases substantially with increasing field intensity (Table II). An X-ray diffraction analysis of these three samples revealed that Conc. 1 contained only ilmenite, whereas ilmenite and pseudorutile were present in Conc.2 and Conc.3.

The non-magnetic fraction (Tailing) separated at a field strength of $0.5 \mathrm{~T}$ in the Cook isodynamic magnetic separator contained $28.33 \%$ titanium and $2.3 \%$ iron. Only rutile and zircon was confirmed as being present in this tailing fraction.

\section{Magnetic Separation}

Figures 5 and 6 present the recovery and the grade of titanium and iron in different magnetic fractions, when paramagnetic titanium-bearing minerals were separated from beach sand using induced roll magnetic separator. The titanium grade in the magnetic fraction could be increased from 35.0 to $39.0 \%$ by varying the magnetic field strength from 0.2 to $1.4 \mathrm{~T}$. However, there is a significant improvement in the recovery of titanium with increasing magnetic field from 0.2 to $1.4 \mathrm{~T}$. 


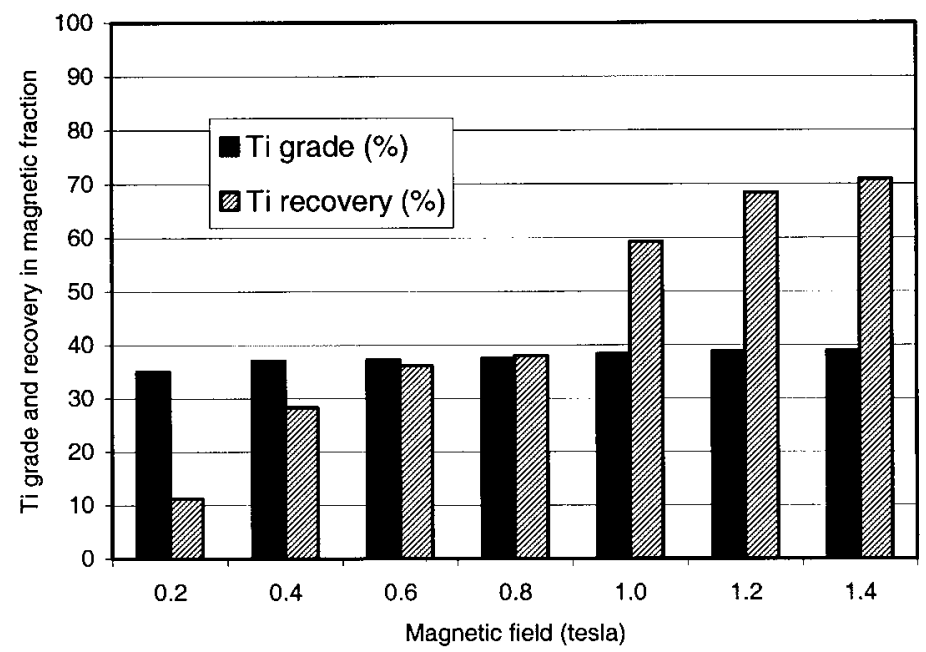

FIGURE 5 Titanium grade and recovery in magnetic fractions with induced roll magnetic separator.

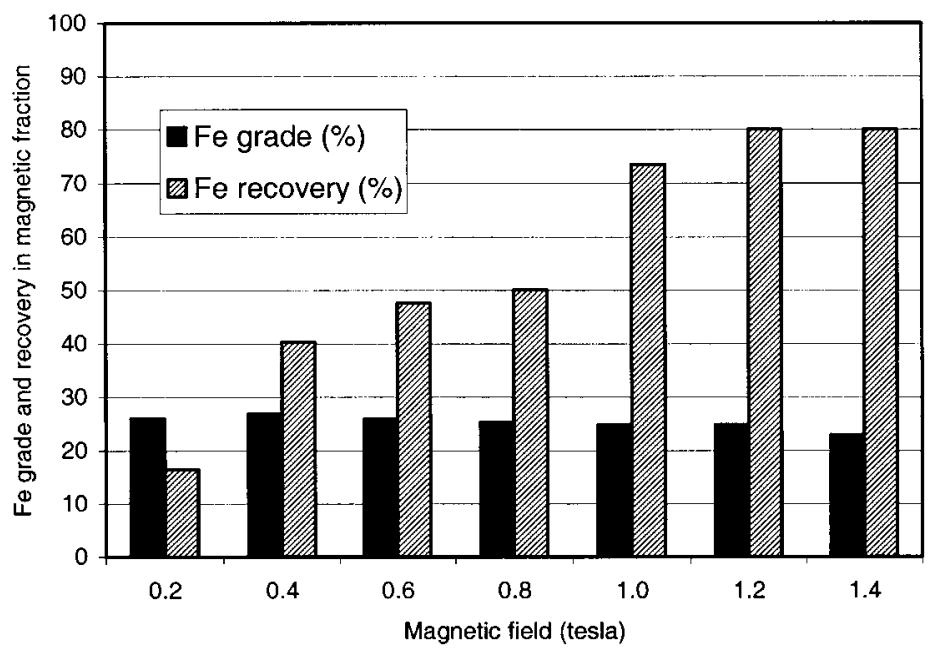

FIGURE 6 Iron grade and recovery in magnetic fractions with induced roll magnetic separator.

The titanium recovery was $11.2 \%$ with a grade of $35.0 \%$ at a field strength of $0.2 \mathrm{~T}$. There is a sudden and significant increase in the recovery of titanium and iron at a magnetic field strength of $1.0 \mathrm{~T}$, giving $59.3 \%$ titanium recovery with a grade of 38.4 and $73.5 \%$ iron recovery with a grade of $24.8 \%$.

However, using the induced roll magnetic separator at the maximum field strength of $1.4 \mathrm{~T}$, the maximum recovery of titanium was $70.9 \%$ with a grade of $39.0 \%(65.0 \%$ $\mathrm{TiO}_{2}$ ), whereas in this fraction the maximum recover of iron was $80.1 \%$ with a grade of $23.0 \%$.

Therefore, a titanium concentrate of commercial standard from the beach sand could be achieved using induced roll magnetic separator at its maximum field strength of 1.4 T. However, there is still recoverable titanium left as ilmenite or pseudorutile in the non-magnetic fraction, separated at $1.4 \mathrm{~T}$ magnetic field strength using the induced 
roll magnetic separator. This is according to the mineralogical analysis of the beach sand deposit and due to only $80.1 \%$ iron being recovered at this point.

Figures 7 and 8 present the recovery and the grade of titanium and iron in different magnetic fractions when paramagnetic titanium-bearing minerals were separated using a disc magnetic separator. In this test work the titanium grade in the magnetic fraction was increased from 33.2 to $38.3 \%$ with increasing magnetic field strength from 0.2 to $0.8 \mathrm{~T}$.

There is a significant increase in the recovery of titanium and iron in the magnetic fraction on increasing the magnetic field strength up to $0.5 \mathrm{~T}$. The recovery and the grade of titanium and iron in magnetic fraction changed slightly from 0.5 to $0.8 \mathrm{~T}$ magnetic field strength. The recovery of titanium was $79.8 \%$ with a grade of $37.6 \%$ and a maximum recovery of $95.7 \%$ iron with a grade of $23.1 \%$ could be achieved at

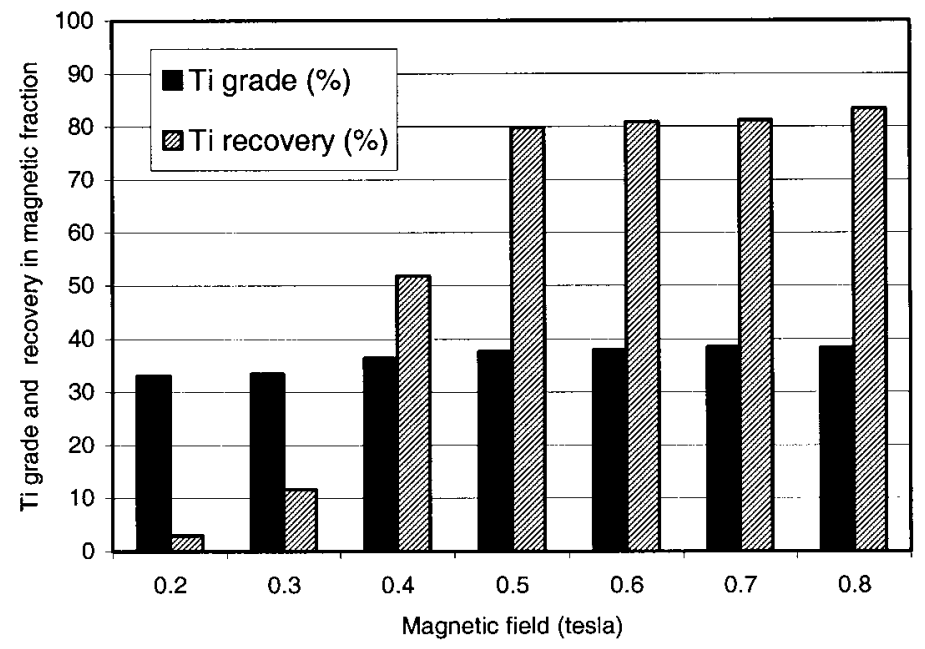

FIGURE 7 Titanium grade and recovery in magnetic fractions with disc magnetic separator.

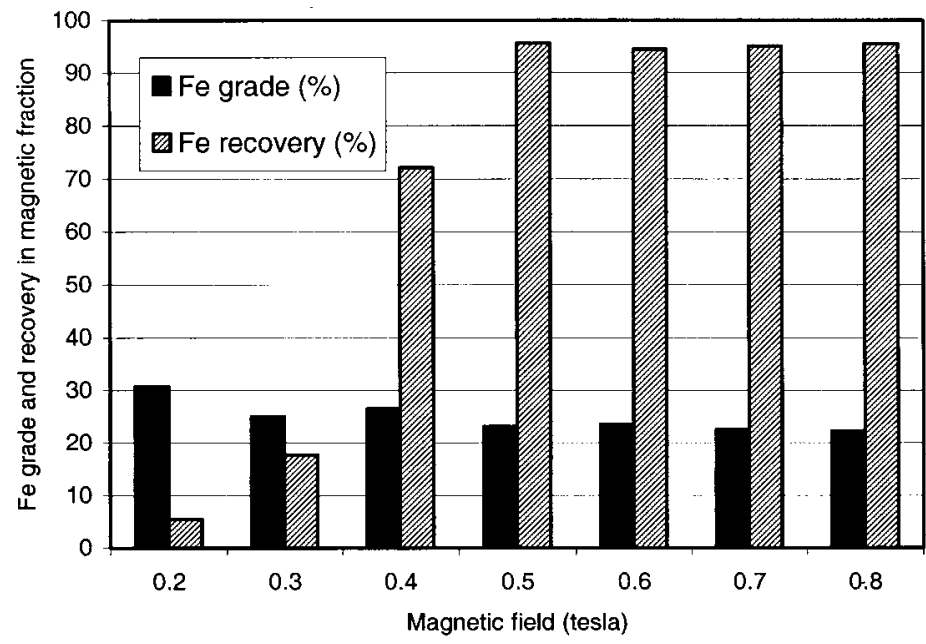

FIGURE 8 Iron grade and recovery in magnetic fractions with disc magnetic separator. 
a magnetic field strength of $0.5 \mathrm{~T}$. The magnetic fraction separated from beach sand at this field strength was $58.0 \%$ by weight.

Figures 7 and 8 show that using the disc magnetic separator at its maximum field strength of $0.8 \mathrm{~T}$, the maximum recovery of titanium was $83.4 \%$ with a grade of $38.3 \%\left(63.9 \% \mathrm{TiO}_{2}\right)$ and the maximum recovery of iron was $95.5 \%$ with a grade of $22.2 \%$. Therefore, a magnetic field strength of $0.5 \mathrm{~T}$ can be considered as the optimum condition for the recovery of paramagnetic titanium-bearing minerals (ilmenite and pseudorutile) from beach sand using the disc magnetic separator.

According to the experimental data, titanium recovery could be improved by more than $12 \%$ with a commercial grade concentrate (up to $63.9 \% \mathrm{TiO}_{2}$ ) using a disc magnetic separator at its maximum field strength of $0.8 \mathrm{~T}$ compared to that from an induced roll magnetic separator. Therefore, using a disc magnetic separator is more economical, effective and efficient for the recovery of titanium from beach sand.

The magnetic force $F_{\mathrm{m}}$ exerted on a particle in a magnetic field is as follows

$$
F_{\mathrm{m}}=\mu_{\mathrm{o}} \kappa V H \nabla H
$$

where $F_{\mathrm{m}}$ is the force $\left(\mathrm{kg} \mathrm{ms}^{-2}\right), \mu_{\mathrm{o}}$ is the permeability of vacuum $\left(\mathrm{kg} \mathrm{ms}^{-2} \mathrm{~A}^{-2}\right), \kappa$ is the volumetric magnetic susceptibility (dimensionless), $V$ is the particle volume $\left(\mathrm{m}^{3}\right), H$ is the field strength $\left(\mathrm{A} \mathrm{m}^{-1}\right)$ and $\nabla H$ is the magnetic field gradient $\left(\mathrm{A} \mathrm{m}^{-2}\right)$.

In a disc magnetic separator, the revolving disc picks up magnetic particles, whereas the gravitational force usually opposes magnetic particle separation with a greater degree of selectivity. The titanium recovery improved significantly with the disc magnetic separator due to the fact that the magnetic field strength and the field gradient (Eq. (1)) can be increased simultaneously and significantly to obtain very precise selective separation compared to the induced roll magnetic separator.

However, in an induced roll magnetic separator, components of the gravitational force and the centrifugal force also act on particles [11] when separating paramagnetic titanium-bearing minerals. One possible way towards increasing the recovery of titanium from beach sand selectively is a multiple pass separation, which is a costly procedure.

\section{CONCLUSIONS}

The following conclusions can be drawn from this study.

It was found that $71 \%$ of raw beach sand was smaller than $355 \mu \mathrm{m}$ in diameter and more than $99 \%$ of titanium content of the deposit was contained in this fraction. Therefore, the fraction with a particle size smaller than $355 \mu \mathrm{m}$ was selected for economical recovery of titanium from the deposit. An X-ray diffraction analysis of the beach sand deposit revealed that only quartz, magnetite, ilmenite, pseudorutile, rutile and zircon minerals were present.

Using the induced roll magnetic separator at the maximum field strength of $1.4 \mathrm{~T}$, the maximum recovery of titanium was $70.9 \%$ with a grade of $39.0 \%\left(65.0 \% \mathrm{TiO}_{2}\right)$. Whereas using the disc magnetic separator at a field strength of $0.8 \mathrm{~T}, 83.4 \%$ titanium was recovered with a grade of $38.3 \%\left(63.9 \% \mathrm{TiO}_{2}\right)$. Therefore, titanium recovery could be improved by more than $12 \%$ using the disc magnetic separator compared to the induced roll magnetic separator. 
Commercial grade titanium concentrates could be achieved employing both induced roll magnetic separator and disc magnetic separator. However, the titanium recovery and grade increased greatly when paramagnetic titanium-bearing minerals were separated from the deposit by a disc magnetic separator. This is more selective, economical, effective and efficient.

\section{Acknowledgements}

One of authors (Premaratne) is indebted to Dr. K.A.S. Pathiratne, University of Kelaniya, for the assistance and supervision provided during the survey and sampling in Sri Lanka. The authors would like to express appreciation to Lanka Mineral Sand Ltd. and the Geological Survey Department of Sri Lanka for providing the samples and for their assistance. ADB Science and Technology Personnel Development Project in Sri Lanka and the Department of Chemical Engineering, University of Birmingham, sponsored this research work.

\section{References}

[1] D.E.D.S. Jayawardena, Asia pacific Ti-minerals distribution and potential, Ind. Min., 367 (1998), $99-107$.

[2] T. Christie and B. Brathwaite, Mineral commodity report 16-Titanium, Institute of Geological and Nuclear Sciences Ltd. http://www.med.govt.nz/crown-minerals/minerals/docs/comreports/report16titanium.pdf (2002).

[3] Anon, Titanium beach sands, Min. Mag., 159(Nov) (1988), 397-405.

[4] M.G.M.U. Ismail, J. Amarasekera and J.S.N. Kumarasinghe, The upgrading of ilmenite from Sri Lanka by the oxidation-reduction leach process, Int. J. Min. Proc., 10 (1983), 161-164.

[5] K. Meyer, Titanium and Zircon placer prospection off Pulmoddai, Sri Lanka, Mar. Min., 4(2-3) (1983), 139-166.

[6] Lanka Mineral Sands Ltd., Company profile, Sri Lanka, 2002.

[7] A.W. Stradling, Development of mathematical model of a cross belt magnetic separator, Min. Eng., 4 (1991), 733-745.

[8] M.M.J.W. Herath, Sri Lanka beach mineral sands, Lanka Mineral Sands Ltd., Ministry of Industrial Development, 1996, pp. 3-12.

[9] P.G. Jeffery and D. Hutchison, Chemical Method of Rock Analysis, 3rd Edn., Pergamon, Oxford, 1981, pp. 21-22, pp. 346-348.

[10] J. Mendham, R.C. Denney, J.D. Barnes and M.J.K. Thomas, Vogel's Textbook of Quantitative Chemical Analysis, 6th Edn., Prentice Hall, England, 2000, pp. 669-670.

[11] A.F. Taggart, HandBook of Mineral Dressing, John Wiley and Sons, New York, 1945, Sec. 13.

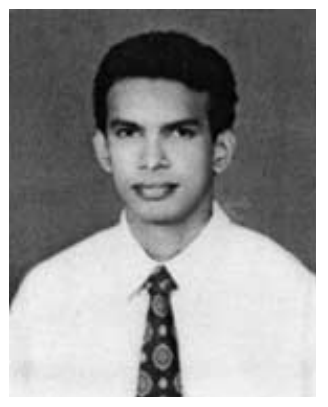

W.A.P.J. Premaratne is a lecturer attached to the Department of Chemistry, University of Kelaniya, Sri Lanka. He is currently studying for his $\mathrm{PhD}$ degree in mineral processing at the Department of Chemical Engineering in the University of Birmingham, UK.

Mr Premaratne completed his B.Sc. special degree in Chemistry in 1997 at the Department of Chemistry in the University of Kelaniya in Sri Lanka. His $\mathrm{PhD}$ research work concerns the extraction of titanium from beach sand deposits using conventional and novel physical and chemical processing methods. 